\title{
Hafnium Resonance Parameter Analysis Using Neutron Capture and Transmission Experiments
}

\author{
MJ Trbovich, DP Barry, RE Slovacck, Y Danon, RC Block, \\ JA Burke, NJ Drindak, G Leinweber, and RV Ballad
}

This report was prepared as an account of work sponsored by the United States Government. Neither the United States, nor the United States Department of Energy, nor any of their employees, nor any of their contractors, subcontractors, or their employees, makes any warranty, express or implied, or assumes any legal liability or responsibility for the accuracy, completeness or usefulness of any information, apparatus, product or process disclosed, or represents that its use would not infringe privately owned rights. 


\title{
Hafnium Resonance Parameter Analysis Using Neutron Capture And Transmission Experiments
}

\author{
Michael J. Trbovich*, Devin P. Barry*, Rudy E. Slovacek ${ }^{\dagger}$, Yaron Danon ${ }^{\dagger}$, \\ Robert C. Block ${ }^{\dagger}$, John A. Burke*, Noel J. Drindak*, Greg Leinweber*, \\ Robert V. Ballad* \\ *Lockheed Martin Corporation, P.O. Box 1072, Schenectady, New York 12301-1072 \\ ${ }^{\dagger}$ Rensselaer Polytechnic Institute, Mechanical, Aerospace and Nuclear Engineering Department \\ Troy, New York 12180-3590
}

\begin{abstract}
The focus of this work is to determine resonance parameters for stable hafnium isotopes in the 0.005 $200 \mathrm{eV}$ region, with special emphasis on the overlapping ${ }^{176} \mathrm{Hf}$ and ${ }^{178} \mathrm{Hf}$ resonances near $8 \mathrm{eV}$. The large neutron cross section of hafnium, combined with its corrosion resistance and excellent mechanical properties, make it a useful material for controlling nuclear reactions.

Experiments measuring neutron capture and transmission were performed at the Rensselaer Polytechnic Institute (RPI) electron linear accelerator (LINAC) using the time of flight method. ${ }^{6} \mathrm{Li}$ glass scintillation detectors were used for transmission experiments at flight path lengths of 15 and $25 \mathrm{~m}$. Capture experiments were done using a sixteen section $\mathrm{NaI}(\mathrm{Tl})$ multiplicity detector at a flight path length of $25 \mathrm{~m}$. These experiments utilized various thicknesses of metallic and isotopically-enriched liquid samples. The liquid samples were designed to provide information on the ${ }^{176} \mathrm{Hf}$ and ${ }^{178} \mathrm{Hf}$ contributions to the $8 \mathrm{eV}$ doublet without saturation.

Data analysis was done using the R-matrix Bayesian code SAMMY version M6 beta. SAMMY is able to account for experimental resolution effects for each of the experimental setups at the RPI LINAC, and also can correct for multiple scattering effects in neutron capture yield data. The combined capture and transmission data analysis yielded resonance parameters for all hafnium isotopes from $0.005-200 \mathrm{eV}$. Resonance integrals were calculated along with errors for each hafnium isotope using the NJOY [1] and INTER [2] codes. The isotopic resonance integrals calculated were significantly different than previously published values; however the calculated elemental hafnium resonance integral changed very little.
\end{abstract}

\section{INTRODUCTION}

The focus of this work was to deduce resonance parameters for all stable hafnium isotopes from neutron transmission and capture data. The energy range of the work was from $\sim 0.005$ to $200 \mathrm{eV}$. A specific goal was to more accurately determine resonance parameters for the pair of overlapping resonances near $8 \mathrm{eV}$. This doublet has a significant peak cross section $(\sim 30 \mathrm{~kb})$ and is made up of two overlapping ${ }^{176} \mathrm{Hf}$ and ${ }^{178} \mathrm{Hf}$ resonances, which are separated by less than $0.1 \mathrm{eV}$.

The most recent hafnium cross section experiments in this energy range had been done in 1975 [3]. The advances in electronics, computers and analysis tools make it possible to perform higher resolution experiments and analyses that are more precise.

The neutron transmission and capture experiments described here were done at the Rensselaer Polytechnic Institute Linear Accelerator (RPI LINAC). The RPI LINAC is an L-band traveling wave electron linear accelerator which can produce up to $60 \mathrm{MeV}$ electrons. The pulsed electron beam is used to produce a pulsed neutron source via $\left(\mathrm{e}^{-}, \gamma\right)$ $(\gamma, n)$ reactions in a tantalum target. The pulsed neutron beam is used for neutron capture and transmission experiments. These experiments use the neutron time-of-flight method to obtain energy dependent data. A more detailed description of the experimental setup can be found in reference 4

The data from these experiments was analyzed using SAMMY (version M6 beta) [5], an R-matrix based resonance analysis code, which use a Bayesian fitting method.

This work was done as partial fulfillment of the requirements for a $\mathrm{PhD}$. Details of this work can be found in reference 6 .

\section{DESCRIPTION OF WORK}

\section{Experimental Setup}

Transmission experiments were performed using 15 and 25 meter detector stations at the RPI LINAC. The detectors used were ${ }^{6} \mathrm{Li}$ glass scintillators, optically coupled to photomultiplier tubes (PMTs). The 15 meter detector setup is optimized for thermal neutron energy experiments $(\sim 0.001$ to $10 \mathrm{eV})$. The 25 meter station is used for neutron transmission experiments above $10 \mathrm{eV}$, referred to as epithermal experiments. Each of the transmission experimental setups uses a computer controlled, eight position sample holder. 
Capture experiments were done using the RPI Multiplicity Detector [7]. This detector is a 16 segment $\mathrm{NaI}(\mathrm{Tl})$ crystal detector located 25 meters from the neutron target. The crystals are arranged as a right cylinder with a center annulus. The centerline of the annulus is aligned with the neutron beam. Each segment is coupled to a PMT and optically isolated. The annulus contains a ${ }^{10} \mathrm{~B}_{4} \mathrm{C}$ liner to shield the crystals from neutrons scattered by the sample. The samples are positioned inside of the detector using a computer controlled, eight-position sample holder.

These experiments used neutron production targets designed for the energy range of interest of each experiment. The Enhanced Thermal Neutron Target [8] was used for all thermal energy range experiments. The Bounce [9] and Bare Bounce [10] targets were used for the epithermal experiments.

Signals from each of the detectors are connected to a neutron time of flight clock. This clock uses a 32 $\mathrm{MHz}$ crystal oscillator to obtain the time of each detector event relative to the start of each pulse. Data is then recorded on an HP1000 data acquisition computer.

\section{Hafnium Samples}

The large variation in peak cross-section of the hafnium resonances required a wide range of sample thicknesses. Metallic samples ranging in thickness from 0.5 to 100 mils ( $1 \mathrm{mil}=0.001 \mathrm{in}$ ) were used in both capture and transmission experiments. These samples were used to cover the incident neutron energy range of 0.005 to $200 \mathrm{eV}$, with the exception of the overlapping pair of resonances near $8 \mathrm{eV}$.

The energy separation between the two ${ }^{176} \mathrm{Hf}$ and ${ }^{178} \mathrm{Hf}$ resonances was too small to resolve using natural samples. Figure 1 shows a plot of the transmission data from a 1 mil natural metallic hafnium sample. As can be seen in Figure 1, the two resonances appear as one due to Doppler and resolution broadening. Isotopically enriched, liquid samples were used to provide data for this region.

The magnitude of the peak cross-section for this resonance pair $(\sim 30 \mathrm{~kb})$ required samples that were extremely thin $(<0.5$ mil metal). Dilute liquid samples were developed to accommodate these thicknesses. These liquid samples were made of a deuterated nitric acid solution of isotopically enriched hafnium. Eliminating the hydrogen (by subtituting deuterium) was important to reduce the scattering cross-section of the diluent. The increased scattering from hydrogen would make it difficult to analyze data from the capture experiments due to multiple scattering effects.

The liquid solutions were contained in quartz cells which were $~ 3 / 32$ ” thick and 1.5 ” in diameter. These cells were designed be mounted in the existing sample holders.

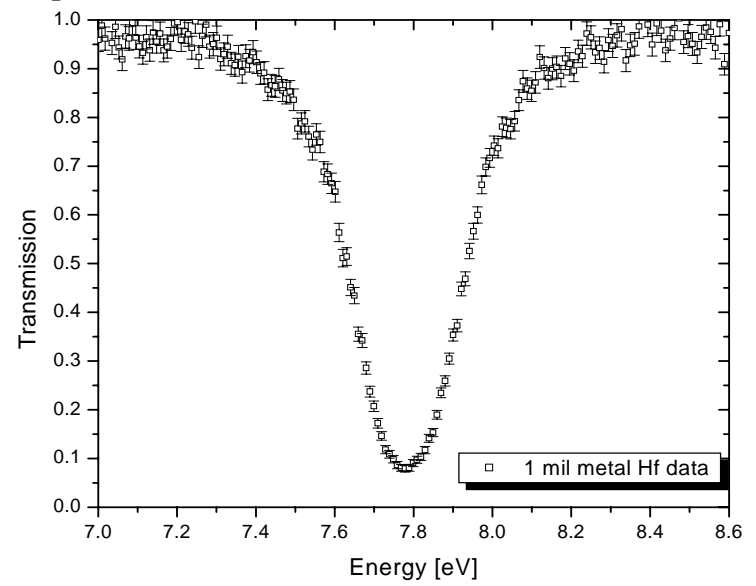

Figure 1: ${ }^{176} \mathrm{Hf}$ and ${ }^{178} \mathrm{Hf}$ resonances in a $1 \mathrm{mil}$ natural metallic hafnium transmission sample

\section{Analysis}

The data analysis for this work was done using the R-matrix, Bayesian resonance analysis code SAMMY. The data from all of the transmission and capture experiments was input into SAMMY. The experimental parameters, including the resolution function, were also quantified and used in the SAMMY analysis. The final resonance parameters from this analysis are the products of a simultaneous fit to multiple samples from multiple experimental data sets.

\section{RESULTS AND CONCLUSIONS}

Data from the transmission and capture experiments using the natural metallic samples were analyzed in the range of 0.005 to $200 \mathrm{eV}$; Figures 2 and 3 show samples of these results. As can be seen in these figures, the fits to the data are of high quality. These fits represent a single set of resonance parameters that provide the best agreement with all of the experimental data.

The data from the metallic samples were used to deduce resonance parameters for over 140 resonances in all stable hafnium isotopes from 0.005 to $200 \mathrm{eV}$, with the exception of the two overlapping resonances near $8 \mathrm{eV}$. The full list of resonance parameters from this analysis can be found in reference 6 .

The data from the isotopically-enriched liquid samples were used to determine resonance parameters for the ${ }^{176} \mathrm{Hf}$ and ${ }^{178} \mathrm{Hf}$ resonances near 8 $\mathrm{eV}$. A portion of this data with the SAMMY fits and the ENDF/B-VI values are shown in Figure 4.

Capture resonance integrals were calculated using the NJOY and INTER codes. The capture resonance integrals calculated using ENDF resonance parameters along with those determined in this work are presented in Table 1. 


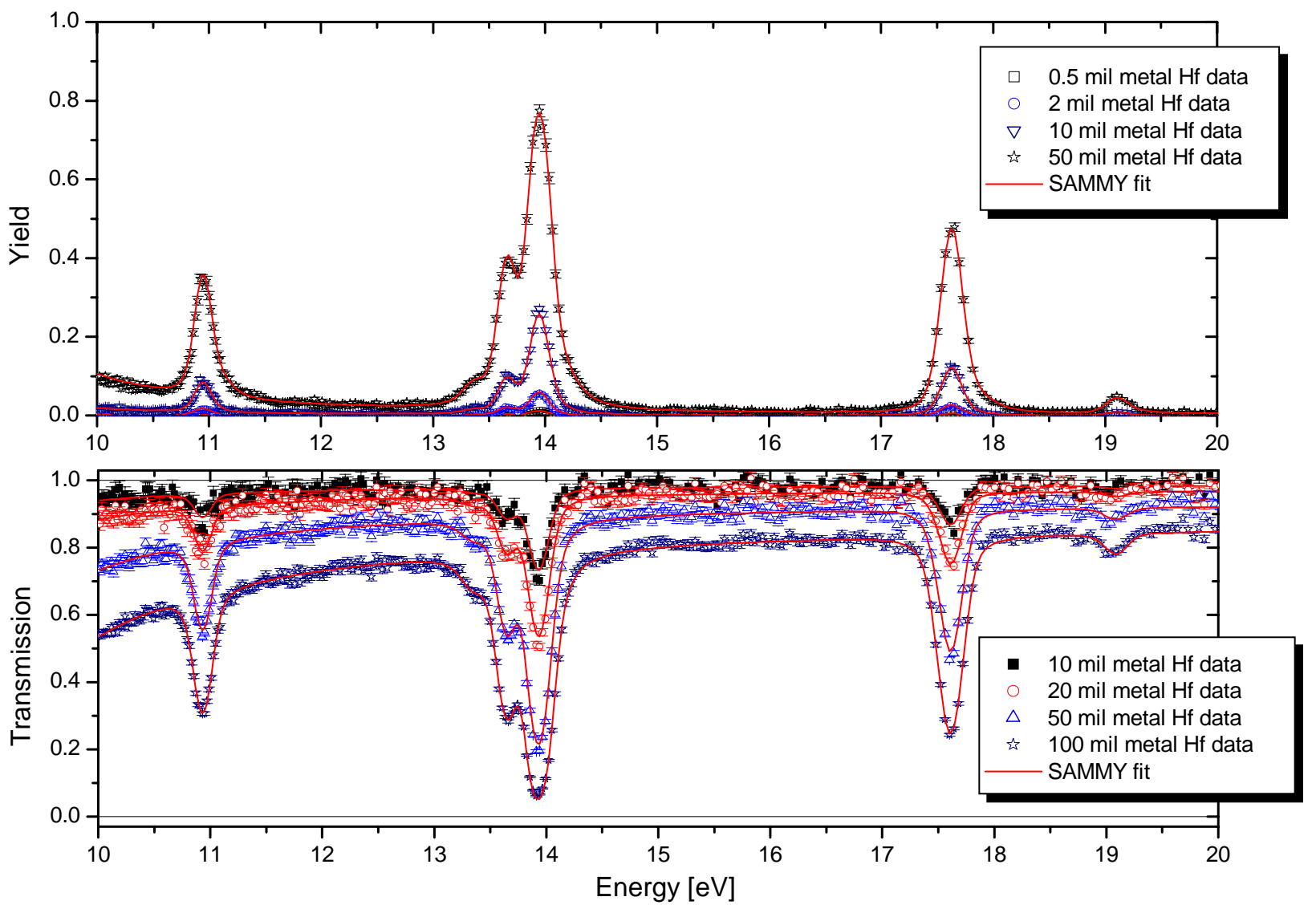

Figure 2: Epithermal capture and transmission data with SAMMY fit for natural metallic samples

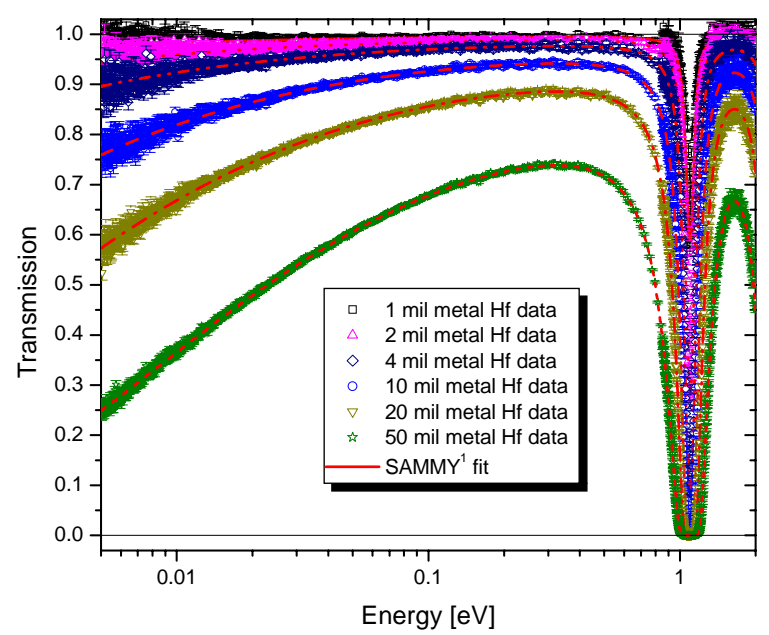

Figure 3: Thermal transmission data with SAMMY fit for natural metallic samples

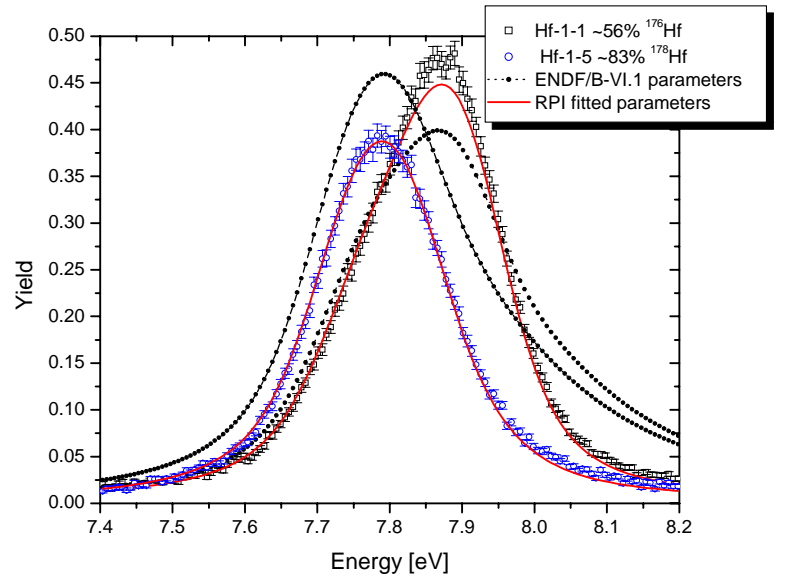

Figure 4: Capture data with SAMMY fits and ENDF/BVI calculated values for isotope enriched liquid Hf samples 
Table 1: Capture resonance integrals based on various resonance parameter sets

\begin{tabular}{|c|c|c|c|c|c|c|c|}
\hline [Values in barns] & Hf 174 & Hf 176 & Hf 177 & Hf 178 & Hf 179 & Hf 180 & Elemental \\
\hline$\underline{\text { JEF-2.2 }}$ & 320.3 & 612.8 & 7232 & 1922 & 543.1 & 35.44 & 1983 \\
\hline$\underline{\text { JENDL-3.2 }}$ & 361.8 & 892.7 & 7209 & 1914 & 521.6 & 33.85 & 1987 \\
\hline$\underline{\text { ENDF/B-VI }}$ & 355.1 & 400.2 & 7221 & 1915 & 548.6 & 34.28 & 1968 \\
\hline$\underline{\text { RPI }}$ & $375 \pm 20$ & $692 \pm 2$ & $7196 \pm 8$ & $1872 \pm 4$ & $506 \pm 3$ & $28.8 \pm 0.1$ & $1959 \pm 2$ \\
\hline
\end{tabular}

The resonance energies determined in this work were found, in most cases, to be close to those previously measured. The capture resonance integral calculated from these resonance parameters is slightly lower, compared to other data sets, for natural hafnium (Table 1). The capture resonance integrals for some of the isotopes changed significantly from previously published values. However, the change in the elemental resonance integral was much smaller.

As anticipated, there are some significant differences in the resonance parameters for the ${ }^{176} \mathrm{Hf}$ and ${ }^{178} \mathrm{Hf}$ resonances near $8 \mathrm{eV}$, these are shown in Table 2. The largest of these differences, compared to ENDF/B-VI, is in the neutron width of the ${ }^{176} \mathrm{Hf}$ resonance at $7.8891 \mathrm{eV}$. The parameters for this pair of resonances quoted in ENDF seem to be based on a single measurement by Moxon [11] in 1974. The neutron width for the ${ }^{176} \mathrm{Hf}$ resonance near $8 \mathrm{eV}$ is reported as $4.71 \mathrm{meV}$, with an error $( \pm 5.5 \mathrm{meV})$ greater than $100 \%$. This is approximately one third the value determined from this work of $10.15 \pm 0.04$ $\mathrm{meV}$. This difference, however, is within the combined errors for these two experiments.

Table 2: ${ }^{176} \mathrm{Hf}$ and ${ }^{178} \mathrm{Hf}$ resonance parameters for the 8 eV pair [errors are given in ()]

\begin{tabular}{|c|c|c|c|c|c|c|}
\hline \multicolumn{2}{|c|}{ Energy (eV) } & \multicolumn{2}{|c|}{$\Gamma_{\gamma}(\mathrm{meV})$} & \multicolumn{2}{|c|}{$\Gamma_{\mathrm{n}}(\mathrm{meV})$} & \multirow{2}{*}{$\begin{array}{l}\text { Isotope } \\
\text { \& Spin }\end{array}$} \\
\hline RPI & Moxon & RPI & Moxon & RPI & Moxon & \\
\hline $\begin{array}{c}7.8891 \\
(0.0003)\end{array}$ & $\begin{array}{l}7.8858 \\
(0.01)\end{array}$ & $\begin{array}{l}61.8 \\
(0.6)\end{array}$ & $\begin{array}{c}57 \\
(12)\end{array}$ & $\begin{array}{l}10.15 \\
(0.04)\end{array}$ & $\begin{array}{l}4.71 \\
(5.5)\end{array}$ & $\begin{array}{l}176 \\
I=0 \\
J=1 / 2\end{array}$ \\
\hline $\begin{array}{c}7.7865 \\
(0.0001)\end{array}$ & $\begin{array}{r}7.7718 \\
(0.0017\end{array}$ & $\begin{array}{l}53.0 \\
(0.2)\end{array}$ & $\begin{array}{l}57.67 \\
(1.6)\end{array}$ & $\begin{array}{l}53.83 \\
(0.08)\end{array}$ & $\begin{array}{l}52.13 \\
(1.42)\end{array}$ & $\begin{array}{l}178 \\
I=0 \\
J=1 / 2\end{array}$ \\
\hline
\end{tabular}

\section{REFERENCES}

1. R. E. MacFARLANE and D. W. MUIR, "The NJOY Nuclear Data Processing System Version 91,” LA12740-M, Los Alamos National Laboratory (Oct. 1994).

2. C. L. DUNFORD, Informal report, "ENDF Utility Codes Release 6.12” (April 2001).
3. H. I. LIOU, J. RAINWATER, G. HACKEN, and U. N. SINGH, Phys. Rev. C, 11, 2022 (1975).

4. RC Block, Y. Danon, R.E. Slovacek, C.J. Werner, G. Youk, J.A. Burke, N.J. Drindak, F. Feiner, J.A. Helm, J.C. Sayres and K.W. Seeman, Neutron Time-ofFlight Measurements at the Rensselaer LINAC, Proc. of Int'l. Conf. on Nuclear Data for Sci. \& Technol., Gatlinburg, Tenesseee, May 9-13, 1994, pp 81-85.

5. N. M. LARSON, "Updated Users Guide for SAMMY: Multilevel R-Matrix fits to Neutron Data Using Bayes’ Equations,” ORNL/TM-9179/R5, Lockheed Martin Energy Research Corporations, Oak Ridge National Laboratory (2000).

6. M. J. TRBOVICH, "Hafnium Neutron Cross-Sections and Resonance Parameter Analysis”, Ph.D. Thesis, Rensselaer Polytechnic Institute (2003)

7. N. J. DRINDAK, “A Multiplicity Detector for Neutron Capture Measurements," Masters Thesis, Rensselaer Polytechnic Institute (1987).

8. Y. DANON, "Design and Construction of the RPI Enhanced Thermal Neutron Target and Thermal Cross Section Measurements of Rare Earth Isotopes,” Ph.D. Thesis, Rensselaer Polytechnic Institute (1993).

9. B. E. MORETTI, "Molybdenum Neutron Transmission Measurements and the Development of An Enhanced Resolution Neutron Target," Ph.D. Thesis, Rensselaer Polytechnic Institute (1996).

10. M. E. OVERBERG, "Development of an Improved Epithermal Neutron Target and Measurement of the Resolution Function to $350 \mathrm{eV}$," MS Thesis, Rensselaer Polytechnic Institute (1997).

11. M. C. MOXON, D. A. J. ENDACOTT, T. J. HASTE, J. E. JOLLY, J. E. LYNN and M. G. SOWERBY, "Differential Neutron Cross-Sections of Natural Hafnium and Its Isotopes for Neutron Energies Up to 30 eV”, United Kingdom Atomic Energy Authority, AERE - R 7684 (1974). 